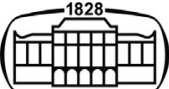

AKADÉMIAI KIADÓ

European Journal of Microbiology and Immunology

11 (2021) 2, 29-43

DOI:

$10.1556 / 1886.2021 .00009$

(c) 2021 The Author(s)

\title{
Antimicrobial resistance of the enteric protozoon Giardia duodenalis - A narrative review
}

\section{ULRIKE LODERSTÄDT ${ }^{1}$ and HAGEN FRICKMANN ${ }^{2,3 *} \odot$}

\author{
${ }^{1}$ Institute for Infection Control and Infectious Diseases, University Medical Center Göttingen, 37075 \\ Göttingen, Germany \\ ${ }^{2}$ Department of Microbiology and Hospital Hygiene, Bundeswehr Hospital Hamburg, 20359 \\ Hamburg, Germany \\ ${ }^{3}$ Institute for Medical Microbiology, Virology and Hygiene, University Medicine Rostock, 18057 \\ Rostock, Germany
}

Received: May 19, 2021 • Accepted: June 17, 2021

Published online: July 8, 2021

\section{REVIEW PAPER}

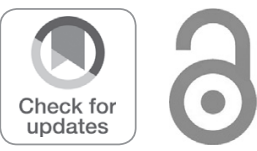

\begin{abstract}
Introduction: As therapy-refractory giardiasis is an emerging health issue, this review aimed at summarizing mechanisms of reduced antimicrobial susceptibility in Giardia duodenalis and strategies to overcome this problem. Methods: A narrative review on antimicrobial resistance in G. duodenalis was based upon a selective literature research. Results: Failed therapeutic success has been observed for all standard therapies of giardiasis comprising nitroimidazoles like metronidazole or tinidazole as first line substances but also benznidazoles like albendazole and mebendazole, the nitrofuran furazolidone, the thiazolide nitazoxanide, and the aminoglycoside paromomycin. Multicausality of the resistance phenotypes has been described, with differentiated gene expression due to epigenetic and post-translational modifications playing a considerable bigger role than mutational base exchanges in the parasite DNA. Standardized resistance testing algorithms are not available and clinical evidence for salvage therapies is scarce in spite of research efforts targeting new giardicidal drugs. Conclusion: In case of therapeutic failure of first line nitroimidazoles, salvage strategies including various options for combination therapy exist in spite of limited evidence and lacking routine diagnostic-compatible assays for antimicrobial susceptibility testing in G. duodenalis. Sufficiently powered clinical and diagnostic studies are needed to overcome both the lacking evidence regarding salvage therapy and the diagnostic neglect of antimicrobial resistance.
\end{abstract}

\section{KEYWORDS}

giardiasis, therapy, resistance, epigenetics, posttranslational modification, resistance testing, Giardia duodenalis

\section{INTRODUCTION}

Giardia duodenalis (also termed G. lamblia or G. intestinalis) is an enteric protozoan parasite with a quite characteristic shape (Fig. 1) of etiological relevance. Human disease, mediated by damage of the enterocytes, loss of the brush border of the epithelial cells of the intestine, shortening of microvilli and altered epithelial barrier function, comprises acute to aqueous diarrhoea, flatulence, steatorrhea, nausea, abdominal pain, vomiting and, as complications in case of chronic disease, malabsorption and weight loss [1]. Especially in resource-poor highendemicity settings, however, infections frequently stay asymptomatic $[2,3]$ as confirmed by studies indicating 50\%-75\% asymptomatic children in high-endemicity areas [4]. Transmission on the faecal-oral route makes the pathogen relevant for hospital and food hygiene [4]. In line with this, enforcement of strict food and drinking water hygiene precautions, e.g., by purification of water in endemicity settings, helps to prevent disease transmission [4]. In Germany, diagnostic proof of $G$. duodenalis is notifiable according to $\S 7$ of infection 


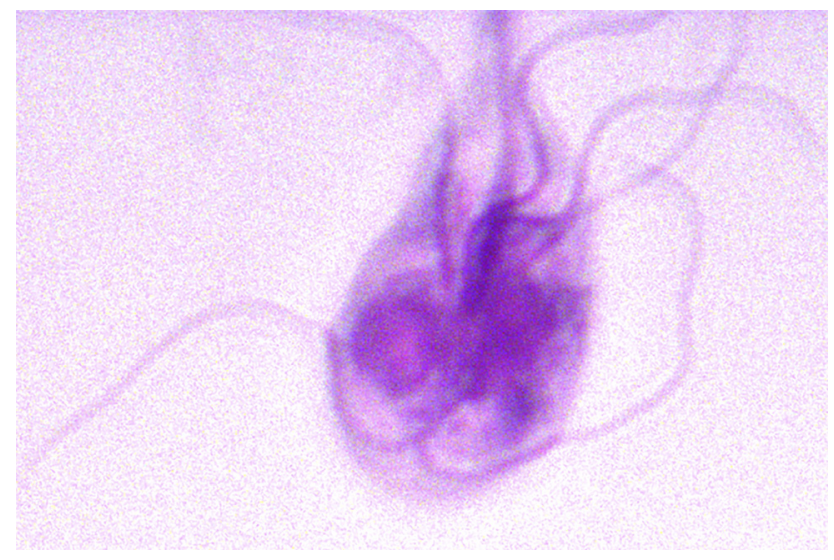

Fig. 1. Typical morphological features of a trophozoite of Giardia duodenalis

prevention law (“Infektionsschutzgesetz"). Identified risk factors, mostly identified in areas of endemicity, comprise day-care for children, working in child-care settings, status as institutionalized individual, travelling in endemic areas, ingestion of contaminated or recreational water, immunodeficiency, cystic fibrosis, and oral-anal sex techniques [4]. In Germany, round about half of detected G. duodenalis infections is imported from abroad, mostly due to travelling under poor hygiene conditions as described for soldiers and police officers without regular access to field camp infrastructure [5-8], for travellers visiting friends and relatives [9], and for migrants [10], respectively.

Microscopy and real-time PCR are the diagnostic procedures of choice [4] with modern real-time PCR assays being considerably more sensitive than microscopy [11] and quite stabile in inter-assay comparisons [11, 12]. Microscopy, in contrast, is investigator-dependent, which is associated with reduced diagnostic reliability even in reference centres as observed in the course of laboratory control trials [13].

Internationally applied treatment options comprise the application of azole compounds like metronidazole or tinidazole as well as nitazoxanide [4]. Although there is no internationally accepted general recommendation for the treatment of asymptomatic patients and there is a therapeutic neglect of this patient group in many countries [4], treatment of asymptomatically infected individuals is usually performed in Germany in order to interrupt transmission chains and infected individuals are prevented from commercial food handling by infection prevention law.

However, resistance or tolerance towards the antimicrobial agents of choice makes the therapy of infection or asymptomatic colonization with $G$. duodenalis challenging [4]. As recently summarized [14], up to 50\% therapy-refractory courses of giardiasis after 5-nitroimidazole (like metronidazole, tinidazole) standard therapy have been reported in international literature $[14,15]$ with hints for an increase in the last decade, particularly in returnees from the Indian subcontinent [16]. Evidence levels of salvage therapy in case of such therapeutic failures like adding of a benzimidazole (like mebendazole, albendazole) to a new therapy course with a 5-nitroimidazole drug or prescribing the anti-malarial drug quinacrine, a substituted acridine with considerable side effects, instead are usually low, just based on small studies or expert opinions [16]. In contrast, sufficiently powered, well designed randomized, doubleblinded, controlled trials are widely missing [14]. In a similar way, large predictor studies for therapeutic failure are unavailable so far [17].

The aim of this narrative mini-review is to summarize present knowledge on antimicrobial resistance in G. duodenalis as well as to highlight the way ahead with focus on therapeutic alternatives.

\section{METHODS}

A selective literature research based on the search words "Giardia" and "resistance" with the database NCBI (National Center for Biotechnology Information) pubmed (https://pubmed.ncbi.nlm.nih.gov/, last accessed at 11th May 2021) was conducted.

\section{HISTORICAL BACKGROUND OF THE TIME BEFORE THE CHANGE OF THE MILLENNIUM}

In the 1960s, nitroheterocyclic drugs including the 5-nitroimidazoles, which depend on reduction by ferredoxin or flavodoxin, became available for the treatment of anaerobic or microaerophilic protozoa lacking mitochondria like $G$. duodenalis $[18,19]$, but their use was early accompanied by the emergence of resistance. Indeed, resistance of G. duodenalis to 5-nitroimidazoles, but also to related nitrofurans requiring nitroreductase activity, has been known for decades $[18,20]$. Thirty years ago, a patient with symptomatic chronic giardiasis was described, who had been cured by a combination of metronidazole and quinacrine after seven courses of monotherapy with metronidazole or quinacrine alone had failed to achieve clinical cure. Thereby, no increased susceptibility of the parasites to the drug combination compared to monotherapy could be shown in vitro but only reduced cellular cytotoxicity of the patient's macrophages for G. duodenalis [21]. Quinacrine, also called metacrine or by its trade name Atebrine ${ }^{\mathrm{TM}}$, was repeatedly successfully used in the 1980s to cure giardiasis patients who had failed to clinically respond to metronidazole [22]. As early as in the middle of the 1980s, when 5-nitroimidazoles like tinidazole and metronidazole still showed low minimum inhibitory concentrations (MIC) for many G. duodenalis isolates, about $50 \%$ of the strains already had increased MICs for alternative drugs like paromomycin, pyrimethamine, and chloroquine, while furazolidone was - in comparison - the most active nonimidazole agent [23]. A linkage between MIC increase for various chemically related substances suggested common mechanisms of resistance [23]. At the beginning of the 1990s, significant variability of in 
vitro susceptibility of different Giardia spp. isolates towards metronidazole and ornidazole was shown. Thereby, decreased in vitro susceptibility was well correlated with therapeutic failure in vivo [24]. Interestingly, metronidazole, although considered as the therapeutic standard for giardiasis, did not have an Food and Drug Administration ("FDA") clearance for this indication in the early 1990s [25]. In 1991, a patient with multidrug-resistant giardiasis was treated at a Swiss hospital. After therapeutic failure with oral administration of metronidazole, tinidazole, ornidazole, and quinacrine, a combination of oral and intraduodenal administration of quinacrine finally cured the patient. Interestingly, no signs of immune deficiency or IgA deficit had been recorded for this patient [26]. In the middle of the 1990s, giardiasis experts called for action in order to prevent resistance dimensions as known from bacterial pathogens in G. duodenalis [27]. In a review published in 2001 [28], nitroimidazoles like metronidazole, tinidazole or ornidazole were still suggested as the treatment of choice due to the broadest respective experience with cure rates $>90 \%$. Quinacrine use was - in spite of comparably good efficacy discouraged due to considerable side effects, furazolidone due its pharmacokinetics requiring application 4 times a day. Due to lack of enteric absorption, paromomycin was suggested for giardiasis requiring therapy in the early pregnancy in spite of its inconsistent therapeutic effectiveness [28].

\section{RESISTANCE MECHANISMS}

Details on the molecular mechanisms of resistance leading to 5-nitroimidazole refractory G. duodenalis infection as well as other resistance types are not yet completely deciphered [14], in spite of considerable effort both with laboratory and clinical strains [29]. Immunodeficiency and IgA deficit in particular as well as hypogammaglobulinaemia in general have been associated with increased risk of therapeutic failure in giardiasis patients $[16,26]$. Also, the organochlorine DDT has been shown to increase G. duodenalis-associated disease severity due to aversive immunomodulating effects in animal experiments [30]. Further, an association of primary treatment failure and increased blood haemoglobin at the time of diagnosis but not with CD4-positive T-cell counts could be shown at least for the subpopulation of HIV-positive giardiasis patients [17].

\section{Induced drug resistance in G. duodenalis}

As early as in the 1980s, it has been described that susceptibility towards metronidazole can be reduced in vitro by constant exposure about several weeks towards sublethal concentrations by factor eight. However, it became also clear by those experiments that the so-induced resistance was unstable and that the protozoa tend to revert to their original metronidazole susceptibility after several weeks of growth without antibiotic pressure [31]. A similar mode of in vitro resistance induction in $G$. duodenalis has been described for other antiparasitic drugs like furazolidone [32], albendazole
[33] and quinacrine [34] as well. Interestingly, it has been demonstrated in vitro that subpopulations of differing resistance levels may exist within defined strains, which show competition when cultured under various degrees of antimicrobial pressure [35]. Thereby, this variability seems to be bigger for nitroimidazoles than for benzimidazoles [35].

\section{Resistance against 5-nitroimidazoles}

Associated with reduced susceptibility, altered intracellular metronidazole concentrations were early recorded, resulting in speculation either on defective transport mechanisms across the cellular membrane or insufficient intracellular reduction of the substance to its biologically active metabolite $[31,36,37]$. The latter is due to modifications of proteins involved in drug activation [38]. In detail, influences of pyruvate:ferredoxin oxidoreductase, ferredoxin pathways and thiol-dependent peroxidase and reductase activities were shown to be of etiological relevance for resistance in $G$. duodenalis [39, 40]. Thereby, reduced cellular concentrations of pyruvate:ferredoxin oxidoreductase as well as downregulation of ferredoxin pathways in G. duodenalis' low-redox-potential anaerobic metabolism lead to decreased metronidazole uptake into the protozoa [40-44]. Also, reduced expression of the oxygen-insensitive nitroreductase1 (ntr-1) gene of $G$. duodenalis may be associated with decreased drug activation, which in turn leads to tolerance towards metronidazole $[44,45]$. $\mathrm{NAD}(\mathrm{P}) \mathrm{H}$ - and flavingenerating pathways and redox-sensitive epigenetic regulation can show similar effects [46]. As a consequence of reduced drug activation, reduced production of radicals that can form adducts with proteins such as thioredoxin reductase and $\alpha$ - and $\beta$-giardins as well as DNA damage follows, resulting in decreased probability of the trophozoites' death [47]. In addition, low expression of oxygen-detoxification enzymes can allow passive, non-enzymatic metronidazole detoxification mediated by futile redox cycling [44]. Such passive mechanisms are supplemented by active resistance strategies, comprising mechanisms of complete enzymatic detoxification of the pro-drug by nitroreductase- 2 as well as enhanced repair of oxidized biomolecules mediated by thioredoxin-dependent antioxidant enzymes [44]. Of note, not all mechanisms are evenly expressed in all resistant strains. In a recent assessment with three different resistant $G$. duodenalis cell lines, common mechanisms comprised upregulating of genes encoding for variant-specific surface proteins, a high cysteine membrane protein, calcium and zinc channels, a Mad- 2 cell cycle regulator and a putative fatty acid $\alpha$-oxidase as well as down-regulated genes encoding nitroreductase-1, putative chromate and quinone reductases, as well as numerous genes that act proximal to the gene encoding the pyruvate:ferredoxin oxidoreductase. In contrast to those similarly regulated genes, a cell line with increased passive resistance mediated by a nonsense mutation in nitroreductase- 1 transcripts showed increased transcription of nitroreductase-2 and a MATE transmembrane pump system, supporting active drug detoxification and 
efflux, respectively. Lines without this mutation had to cope with a higher oxidative stress load caused by metronidazoleand oxygen-derived radicals [44]. In addition, it has been suggested that posttranslational modifications like protein acetylation, methylation, ubiquitination, and phosphorylation play a role in metronidazole resistance [48]. More than this, it has been shown that metronidazole fails to arrest the cell cycle progression in resistant strains while it shows this effect in susceptible ones [49]. Other than reported for metronidazole resistance in Trichomonas vaginalis, however, measurably defective $\mathrm{O}_{2}$-scavenging capabilities compared to metronidazole-sensitive isolates were not reported for $G$. duodenalis, although elevated NADPH-oxidase activities have been shown for metronidazole-resistant G. duodenalis strains [50]. Of note, metronidazole resistance in G. duodenalis is accompanied by a glucose metabolism-related attachment defect to mucosal cells. So, metronidazoleresistance appears to be evolutionarily balanced against the infectious potential of a G. duodenalis strain [51]. Altogether, polygenically mediated changes in the antioxidant network, glycolysis, and electron transport affect metronidazole resistance, which is also influenced by protein acetylation as indicated by cross-resistance to the deacetylase inhibitor trichostatin A [48].

\section{Co-resistance against metronidazole and nitozoxanide}

Co-resistance against metronidazole and nitazoxanide was found to be associated with changed expression of stress response-related and heat shock proteins (HSP70 B2, HSP40), major surface antigens such as the variant surface protein (TSA417, AS7), nitazoxanide-binding proteins like nitroreductase 1 (GINR1) and the protein disulphide isomerase PDI4 $[43,52,53]$. Interestingly, as observed with a $G$. duodenalis strain expressing this resistance type, a cycle of en- and excystation leads to vanishing or resistance, suggesting epigenetic changes rather than changes of the DNA sequence to be responsible for the resistance pattern [52]. Further, in a cell line with stabile co-resistance to the nitrocompounds metronidazole and nitazoxanide, multiple metabolic adaptations were observed. They comprised a reduction of the activities of FAD-dependent oxidoreductases, lower nitroreductase activities, lower oxygen consumption and resazurin reduction rates, lower ornithinecarbamyl-transferase activity, reduced FAD and NADP $(\mathrm{H})$ pool sizes and higher ADP/ATP ratios, respectively, compared to the wildtype [54]. As resistance against nitro drugs is mediated by several distinct mechanisms and not the consequence of a directed process, it is consequently not correlated with a specific pattern of differentially expressed proteins as demonstrated with mass spectrometry shotgun analysis of the proteomes of distinct nitro drug-resistant strains [55].

\section{Resistance against benzimidazoles}

Albendazole resistance, which is associated with parbendazole cross-resistance, is reported to be mediated by alterations of the cytoskeleton of G. duodenalis with particular emphasis on the median body [56]. In particular, alterations of the so-called ROD-domain of the beta-giardin protein have been associated with albendazole resistance [57]. Further, efflux of both albendazole and nitazoxanide from $G$. duodenalis cells has been shown to be mediated by proteins of the ATP-binding cassette (ABC) transporter superfamily, in particular with the $\mathrm{ABC}-\mathrm{C} 1$ transporter, also known as multidrug resistance protein 1 [58]. In addition and next to $\beta$-tubulin changes in albendazole-resistant $G$. duodenalis, pro-oxidant cytotoxicity of albendazole is counteracted by an increased antioxidant response involving reactive oxygen species-(ROS-)metabolizing enzymes (NADH oxidase, peroxiredoxin 1a, superoxide dismutase and flavodiiron protein) and higher levels of intracellular free thiols [59].

\section{Resistance against other therapeutic drugs for giardiasis}

The thiol cycling enzymes mediate furazolidone resistance [41], while metronidazole only slightly reduces the thiol pool even within susceptible G. duodenalis strains [60]. Quinacrine resistance has been reported to be associated with active exclusion from resistant trophozoites. Of note, G. duodenalis strains with pre-existing furazolidinone resistance tend to adapt more quickly to increasing quinacrine concentrations as well [34].

\section{HINTS FOR GENETIC VERSUS EPIGENETIC DETERMINANTS OF RESISTANCE IN G. DUODENALIS}

There are no well-defined resistance genes to be used for diagnostic purposes like, e.g., for methicillin-resistance in bacteria of the species Staphylococcus aureus [61]. This is well in line with lacking stability of resistance induction in the absence of selective pressure by the antimicrobial drug as early observed [31]. Instead, redox-sensitive epigenetic regulation is discussed [46] and molecular resistance mechanisms are likely to be largely founded on reversible transcriptional changes. This, in addition to posttranslational modifications, best explains the observed phenomena that resistant lines revert to drug sensitivity during drug-free culture in vitro or during passage through the life cycle $[44,48]$.

\section{Nitroimidazole resistance}

Matching the abovementioned, metronidazole resistance induced by long-term growth of G. duodenalis with sublethal metronidazole doses can occur completely without mutations in metronidazole resistance-associated genes like pfor, $f d, n r-1$ or $\operatorname{trxr}$ [62]. Nevertheless, some associations have been described. Genomic sequencing of various strains of the G. duodenalis assemblages A and B showed that, even irrespective of individual metronidazole resistance, genetic variability is common in important genes in metronidazole metabolizing pathways and in the management of oxidative 
and nitrosative stress, including high numbers of non-synonymous (amino acid-changing) single nucleotide polymorphisms [63]. Also, rearrangements on the chromosome and repetitive DNA level have been early seen in metronidazole resistant G. duodenalis strains [41]. In particular, the loss of the 3000-base pair-sequence G6/1 on chromosome 4 of G. duodenalis, which seem to interfere with cell division of the parasite, has been associated with the onset of metronidazole resistance [64]. Increased levels of expression of the gene for protein disulphide isomerase 2 (PDI2) has been described for strains resistant against either metronidazole or nitazoxanide, while combined resistance was also associated with PDI4 expression. Also, drastic changes in the expression of genes for variant surface proteins (VSP) in strains resistant against those substances have been reported [65]. Altered expression of pfor RNA, coding for the pyruvate:ferredoxin oxidoreductase, was identified in metronidazole resistant strains [66]. However, altered pfor RNA expression levels were only found in case of severe metronidazole resistance and the association was generally weak, so pfor expression is a poor diagnostic marker of metronidazole resistance [67]. More than this, this mechanism does not seem to be a necessary condition for metronidazole resistance at all, as it was found to be completely absent in highly 5-nitroimidazole resistant G. duodenalis strains [68, 69]. Indeed, a multi-factorial nature of metronidazole resistance was confirmed by the identification of strains, in which impaired flavin metabolism played the major role for nitroimidazole resistance, mediated by the flavin-dependent G. duodenalis thioredoxin reductase (GlTrxR) and the NADPH oxidase [69]. Interestingly, resistance associated changes in the expression of stress response-related and heat shock proteins (HSP70 B2, HSP40), major surface antigens such as the variant surface protein (TSA417, AS7) as well as the nitazoxanide-binding proteins nitroreductase and protein disulphide isomerase PDI4 can vanish after an en- and excystation cycle, confirming epigenetic changes rather than persistent changes of the DNA sequence [52]. Metronidazole-induced cellular stress leads to downregulation of the antioxidant system and $\alpha$-giardins, while associated resistance-development is believed to be influenced by multiple epigenetic mechanisms of transcriptional control as suggested by antisense de-repression and differential regulation of RNA [70]. However, it has been suggested that accelerated mutagenesis resulting from metronidazole-induced DNA damage might also contribute to resistance development [71], mediated by triggering the parasite's DNA homologous recombination repair pathway [47]. In line with this, in a metronidazole-resistant $G$. duodenalis cell line, a nonsense mutation in nitroreductase- 1 transcripts has been observed, which supports metronidazole resistance but is not a necessary condition for such resistance by itself [44].

\section{Benzimidazole resistance}

Associated with albendazole resistance [56], chromosome rearrangements affecting the cytoskeleton structure were observed, but without coding for a tyrosine for phenylalanine amino acid exchange at position 200 in beta-tubulin, which has been described for benzimidazole-resistance in helminths and fungi, or other consistent sequence changes in the target structure beta-tubulin [56, 59, 72]. However, permanent sequence changes in the beta-giardin gene, resulting in amino acid changes in the protein's ROD domain from TIARERA to IDRPRE, have also been associated with reduced susceptibility to albendazole [57]. Further, RNA of the variant surface protein ARR-VSP was found to be upregulated in albendazole resistant G. duodenalis clones [66]. Altogether, the differential expression of several genes for proteins playing a role in maintaining cell structural stability, coping with oxidative stress and adapting energy supply to altered metabolic states is crucial for albendazole resistance. The affected proteins comprise proteins with functional roles not only in the cytoskeletal system (alpha 2-giardin and RanBP1) but also in the antioxidant metabolism (NADH oxidase) and in the energy metabolism (triosephosphate isomerase, phosphoglycerate kinase and ornithine carbamoyltransferase), respectively [73].

\section{Resistance against other drugs}

Changes in the expression of the variant surface protein as well as reduced expression of the parasite's nucleoside hydrolase $(\mathrm{NH})$ are considered to be responsible for resistance against isoflavones like daidzein and formononetin [74]. Increased transcription of the neomycin phosphotransferase $(n e o(r))$ gene is known to mediate resistance against the aminoglycoside G418 (geneticin) in G. duodenalis [75].

\section{TREATMENT ATTEMPTS ALTERNATIVE TO THE "5-NITROIMIDAZOLES STANDARD"}

Natural and synthetic substances with giardiacidal effects were early tried to identify $[76,77]$ and those efforts proceeded with ongoing resistance issues [78].

\section{Alternative nitroheterocyclic substances}

Although there is considerable cross-resistance between nitroimidazoles in G. duodenalis, there are also substancespecific differences, making it worth testing various substances of the group for potential therapeutic success [51, 79-81]. The ongoing effort for optimizing nitroimidazoles in order to overcome metronidazole resistance have shown that easier redox activation is positively correlated with greater giardicidal activity. For example, olefins with a conjugated bridge connecting the core and a substituted phenyl or heterocyclic ring were identified as promising options [82]. In vitro assessments also suggested high effectiveness of 2lactam-substituted 5-nitroimidazoles for the treatment of $G$. duodenalis [79]. A modification based on a side chain carrying a remote phenyl group in the 2-position of the imidazole ring was found to be 14 -fold more active against $G$. duodenalis than metronidazole [61]. Metronidazole-triazole conjugates and nitroimidazole carboxamides were also able 
to overcome some types of metronidazole resistance in vitro [83, 84]. Parasite cell vesicle trafficking, autophagy, and triggered differentiation into cysts are processes which are targeted by modern metronidazole derivates for giardiasis treatment [85]. In silico drug design offers new options of designing nitroheterocyclic drugs with therapeutic effects against giardiasis. In addition to nitroimidazoles, such nitroheterocyclic drugs also comprise nitropyrroles and nitrofurans [86]. The nitrofuran furazolidone has been shown in vitro to provide more severe damage than metronidazole to cyst stages of G. duodenalis, associated with morphological alterations like the presence of cavities, lamellar bodies as well as thread-like structures and inhibition of in vitro cyst differentiation [87]. Similar like metronidazole but other than nitazoxanide, furazolidone uses the parasite's antioxidative enzyme thioredoxin reductase to be converted into its active form which is toxic to G. duodenalis [88].

\section{Benzimidazoles}

In vitro experiments with G. duodenalis suggested 30- to 50fold higher activity of albendazole and mebendazole compared to metronidazole and 4- to 40-fold higher activity compared to quinacrine, respectively, while thiabendazole scored poorer. Static in vitro effects have been reported for mebendazole, which shows poor intestinal absorption and interacts with the microtubules of the parasite even at lower concentrations than required for the standard agent metronidazole [89]. In detail, microtubule polymerization is inhibited through selective binding to the $\beta$-tubulin subunit [72]. Of note, the giardicidal effects of different benzimidazoles and tubulin inhibitors vary. While mebendazole, albendazole and fenbendazole have been described to induce irreversible effects on the cells, only transient effects have been reported for nocodazole, oxfendazole, and albendazole sulfoxide, respectively [90]. At least in calves, effective eradiation of Giardia cysts from stool due to fenbendazole therapy has been shown in vitro, but reoccurrence within 4 weeks after treatment suggests occasional need for repeated therapy [91]. Further, in vitro experiments suggested increased activity of S-substituted 4,6-dibromo- and 4,6dichloro-2-mercaptobenzimidazoles against G. duodenalis compared to metronidazole [92]. Therapeutic activity of benzimidazoles against $G$. duodenalis can further be increased by the combination with phenyl-carbamates, which has been discussed as an option for strains with reduced susceptibility for benzimidazoles [93]. Albendazole, in particular, also partially inhibits encystation and, to a lower degree, excystation [94]. Such interruption of the parasitic life cycle is considered to be important for the prevention of the spread of giardiasis [95]. While showing therapeutic effects on giardiasis comparable to metronidazole, albendazole has the advantage of lower side effect rates [96]. Chemically modified benzimidazole derivates have been shown to allow higher activity against G. duodenalis and may be suitable therapeutic alternatives for the future [51]. In benzimidazole-susceptible $G$. duodenalis cells, albendazole induced oxidative stress results in DNA damage as indicated by $8 \mathrm{OHdG}$ adducts, DNA degradation and histone $\mathrm{H} 2 \mathrm{AX}$ phosphorylation, partial arrest within the cell cycle, and subsequent induction of apoptosis associated with phosphatidylserine exposure on the parasite surface [97].

\section{Nitazoxanide}

In vitro activity of the thiazolide nitazoxanide [2-acetolyloxy-N-(5-nitro 2-thiazolyl) benzamide] against G. duodenalis has been thoroughly assessed since 2001. Nitazoxanide induced changes in trophozoite volume, loss of characteristic shape and swelling, but the effects were less severe in direct comparison to tinidazole [98]. Both nitazoxanide and its metabolite tizoxanide were shown to be considerably more active than metronidazole in metronidazole-susceptible $G$. duodenalis strains and at least slightly more active in metronidazole resistant strains [99], which is not surprising as resistance formation in G. duodenalis against nitazoxanide and metronidazole is linked, most likely due to altered gene expression [65]. In spite of this, successful treatment of a giardiasis patient with HIV co-infection and a G. duodenalis isolate resistant to metronidazole and albendazole by application of nitazoxanide could be demonstrated [100]. Nitazoxanide is known to inhibit the protein disulphide isomerases PDI2 and PDI4 of G. duodenalis [65]. Nitroreduction and free radical production are the likely modes of giardicidal action, because analogues lacking the reducible nitro-group showed reduced activity [99]. Further, the giardicidal effect of nitazoxanide was shown to be partially mediated by activation of the nitroreductase GINR1 [101].

\section{Quinacrine}

In spite of considerable side effects, the antimalarial drug quinacrine had a renaissance in the treatment of nitroimidazole-resistant giardiasis. In a retrospective assessment at the London School of Hygiene and Tropical Medicine, London, United Kingdom, $100 \%$ of cases of metronidazolerefractory giardiasis could be successfully cured with quinacrine. Of note, however, those data were from a retrospective assessment and the sample size ( $\mathrm{n}=20$ patients) was small [16]. However, $100 \%$ therapeutic success with quinacrine in 13 giardiasis patients, infected with strains of the assemblages A and B as identified by PCR, after failed nitroimidazole therapy was reported from Spain as well [102]. Similarly, 15 out of 15 patients with nitroimidazolerefractory giardiasis were successfully treated with quinacrine in Cuba [103].

\section{Antibiotics and anti-viral substances}

As predicted from the sequence of ribosomal RNA and subsequently confirmed in vivo, the aminoglycosides hygromycin and paromomycin can successfully inhibit the growth of wild-type strains of $G$. duodenalis. This is, however, not a group-specific, but a substance-specific effect, as growth inhibition cannot be achieved with other aminoglycosides like kanamycin or apramycin in the same way [104]. Altogether, sequences within domain V of 
G. duodenalis' large-subunit rRNA resemble archaebacterial rRNA, suggesting a high level of evolutionary conservation [105]. Paromomycin susceptibility of $G$. duodenalis is considered to be associated with the presence of a C:G basepair near the decoding region of the small subunit ribosomal RNA [106].

In vitro, ciprofloxacin as well inhibits $G$. duodenalis growth, adherence and $\mathrm{O}_{2}$ uptake in a concentrationdependent manner and finally leads to death of the G. duodenalis trophozoites due to a necrosis process. Based on those in vitro results, ciprofloxacin has been discussed as a potential option for therapy-refractory giardiasis [107].

While high concentrations of the macrolide azithromycin are required of achieve growth inhibition of G. duodenalis, hundred-fold lower concentrations are sufficient for adherence inhibition [108]. Thereby, however, azithromycin susceptibility varies considerably in different strains [41].

Bacitracin shows in vitro inhibiting effects on G. duodenalis which can be increased by zinc substitution [109].

Interestingly, also some anti-retroviral protease inhibitors, in particular ritonavir-boostered lopinavir (trade name Kaletra ${ }^{\mathrm{TM}}$ ), show therapeutic effect against $G$. duodenalis. While standard dosage of ritonavir alone can also inhibit G. duodenalis, lopinavir alone is insufficient for complete inhibition but at least results in blockage of cytokinesis in G. duodenalis trophozoites [110].

\section{Anti-rheumatic and anti-tumoral substances}

The antirheumatic drug auranofin eradicated G. duodenalis in different rodent models by blocking the activity of giardial thioredoxin oxidoreductase and thus by interfering with normal protein function and with combating oxidative damage [111]. The membrane-active alkylphospholipid hexadecylphosphocholine (miltefosine), which has been developed as an anti-tumoral drug and which is nowadays applied to cure visceral leishmaniasis, eliminates giardiasis in the mouse model by affecting the parasites' cellular membrane and adhesive disc [112]. Another anti-tumoral compound with in vitro giardicidal effects is NBDHEX, which is active on several levels in G. duodenalis trophozoites, comprising inhibition of glycerol-3-phosphate dehydrogenase, binding to metabolic enzymes like thioredoxin reductase $(\mathrm{g} \operatorname{TrxR})$, elongation factor $1 \mathrm{~B}-\gamma(\mathrm{gEF} 1 \mathrm{~B} \gamma)$, and structural proteins like $\alpha$-tubulin. Thioredoxin reductase, in particular, is able to nitroreduce NBDHEX leading to drug modification of catalytic cysteines in thioredoxin reductase, with concomitant disulphide reductase activity inhibition and NADPH oxidase activity upsurge, resulting in increased toxicity of the compound [113].

\section{Synergistically acting drugs, drug combinations and hybrid compounds}

Synergistic effects on adherence inhibition of G. duodenalis were observed for dyadic combinations of azithromycinfurazolidone, doxycycline-mefloquine, doxycycline-tinidazole, and mefloquine-tinidazole, respectively, suggesting increased therapeutic effects of such combinations [108]. Further in vitro synergistic action could be shown for albendazole and the synthetic derivatives 2-aryl-3-hydroxymethylimidazo[1,2-a]pyridine and -pyrimidine against G. duodenalis trophozoites [114].

Synergisms have not only been shown in vitro. Also, there are hints for clinical superiority of combination therapy in patients with therapy-refractory giardiasis, although evidence is scarce $[115,116]$. In a small group of giardiasis patients who could not be cured with metronidazole therapy, combination of albendazole plus metronidazole was superior to albendazole alone [117]. In a review from 2001, prolonged application of a combination of nitroimidazole and quinacrine was recommended for patients with resistant giardiasis [28], as therapeutic success was repeatedly observed with this approach $[28,118]$. Combination therapy of mebendazole plus secnidazole was successfully applied as a salvage therapy for patients with nitroimidazole-resistant giardiasis as well [103].

As a comparatively new approach, hybrid compounds created by combining different giardicidal drugs within one molecule have been introduced [119]. For example, CMC20 , a nitazoxanide and $\mathrm{N}$-methyl-1H-benzimidazole hybrid molecule, showed giardicidal effects in G. duodenalis strains resistant against albendazole or nitazoxanide alone by affecting the parasite's microtubule reservoir, triggering the parasite's encystation and alpha-7.2 giardin co-localization with CWP-1 protein in vitro and in the murine model [120].

\section{Herbal preparations}

Herbal treatment approaches have been assessed as promising options for therapy-refractory giardiasis as well [121]. In India, Pippali rasayana, prepared from Piper longum and Butea monosperma, has been tested for giardicidal effects in mice. The substance did not affect the parasite itself but increased both the macrophage migration index (MMI) and the macrophages' phagocytic activity, resulting in $98 \%$ recovery of the mice from $G$. duodenalis infection [122]. The component (-)-epigallocatechin from the plant Helianthemum glomeratum, which had already been used in Mayan traditional medicine for the treatment of diarrhoea, shows growth inhibiting potential against G. duodenalis in vitro [123]. Lippia beriandieri (oregano) has been reported to lead to giardicidal effects in vitro even more pronounced than observed with tinidazole, resulting in damage of nucleo-skeleton proteins associated with an altered structure of the nucleus as well as in deterioration of size and shape of G. duodenalis trophozoites [124]. Reduction of the MTTtetrazolium salt levels is believed to be one mode of giardicidal action of oregano. Naringenin, thymol, and pinocembrin were identified among oregano's giardicidal components [125]. Polyphenolic-rich blueberry extract leads to a dose-dependent reduction of $G$. duodenalis trophozoite viability; the polyphenols are considered as the components in charge of the reduced survival of the parasites [126]. In mouse experiments, dichloromethane extracts of Zingiber officinale (ginger) and Curcuma longa (curcumin) showed 
therapeutic effects against giardiasis. Thereby, the giardicidal effect of ginger was more pronounced than the effect of curcumin [127]. In vitro assessment also indicated a dosedependent giardicidal effect of a chloroformic extract of Artemisia annua [128, 129]. Olive leaf extracts and extracts of Satureja khuzestanica (a plant used for medical purposes by nomads in southwestern Iran) show in vitro giardicidal effects in the range of metronidazole or better [130]. In contrast, Allium sativum (garlic) scores poorer in vitro, discouraging its therapeutic use [130]. Also, methylgerambullin, a sulphur-containing amide in Glycosmis spp. (family Rutaceae) [131], 2,3-Dihydroxyphenyl B-D-glucopyranosiduronic acid as well as the tannins gallic acid and chebulic acid extracted from Terminalia ferdinandiana in combination with ascorbic acid, respectively [132], and crude Ageratum conyzoides extracts [133] showed giardicidal effects in vitro and partly also in animal experiments. The giardicidal effects of the latter were associated with changes in the flagella and the ventral discs of G. duodenalis trophozoites [133].

\section{Milk and milk components}

In the 1980s, a giardiacidal effect of non-heated human but not of non-heated cow's or goat's milk on G. duodenalis trophozoites has been observed, most likely mediated by the heatsensitive fatty acid esterase bile salt-stimulated lipase (BSL) [134]. However, a clinical application has never been successfully implemented. Further, it is believed that both human and bovine lactoferrin, particularly the $\mathrm{N}$-terminal peptides, may be of relevance as a nonimmune component of host mucosal defence against $G$. duodenalis due to its giardicidal activity. However, the presence of $\mathrm{Fe}^{3+}$ ions can protect $G$. duodenalis trophozoites from this effect in vitro [135].

\section{Others}

G. duodenalis' glycolytic enzyme triosephosphate isomerase (GlTIM), next to other glycolysis-specific enzymes of the parasite, have been proposed as potential drug targets. For GITIM, thiol-reactive compounds are under investigation as potential therapeutic drugs [136]. The giardial glycolytic enzyme triosephosphate isomerase is dose-dependently inhibited by the proton pump inhibitor omeprazole, leading to cell death of $G$. duodenalis in vitro [137]. The chemically modified proton pump inhibitors $\mathrm{BHO} 2$ and $\mathrm{BHO} 3$ showed even stronger inhibition of triosephosphate isomerase and associated giardicidal effects, which are mediated by chemical modification of Cys222 and associated structural changes of the enzyme as well as by adducts linked to cysteine residues [138]. Also, disulfiram shows giardicidal effects in vitro mediated by Cys222-modifications of the triosephosphate isomerase of G. duodenalis, thus deteriorating its stability [139]. Giardia carbamate kinases (glCK), which have no equivalent in human cells, are affected by disulfiram and are targets of interest for drug development [139, 140]. KH-TFMDI, a 3-arylideneindolin-2-one-type sirtuin inhibitor, shows in vitro giarcidal effects by inhibiting sirtuins, which are class III NAD+-dependent histone deacetylases, in the parasite. Associated micromorphological changes comprise multinucleated cell clusters suggesting compromised cytokinesis in treated trophozoites, cell rounding, concomitantly with the folding of the ventrolateral flange and flagella internalization, and finally cell death associated with DNA/nuclear damage, formation of multi-lamellar bodies and annexin $\mathrm{V}$ binding on the parasite surface [141]. Also, the five long-chain fatty acyl-CoA synthetases (GiACS1 to GiACS5) of G. duodenalis have been identified as potential drug targets, since the acyl-CoA synthetase inhibitor triacsin $\mathrm{C}$ was shown to inhibit giardial growth in vitro [142]. Giardicidal effects in animal models were recently also demonstrated for selected Hsp90 (heat shock protein 90) inhibitors [143]. Deconjugated bile salts as produced by bacterial bile-salt-hydrolases of the probiotic bacterial strain Lactobacillus johnsonii Lal show giardicidal effects as well, suggesting potential protective effects of probiotic applications [144]. Isoflavones like daidzein and formononetin inhibit G. duodenalis growth [74]. Aminoguanidine compounds like robenidine are associated with in vitro giardicidal effects, inhibiting in vitro adherence of the parasite and damages to the parasite's plasma membrane [145]. New therapeutic substances under investigation comprise so-called "bumped" kinase inhibitors (BKIs). BKIs target protein kinases of G. duodenalis, which have an expanded active site pocket. The latter results from an atypically small gatekeeper residue. Inhibition of those small-gatekeeper kinases is a completely new mode of action, which does not overlap with modes of action exerted by current giardicidal drugs [146]. Even therapeutic effects of the beta receptor blocker propranolol on metronidazoleresistant giardiasis have been assessed [147]. Salinomycin, an ionophore therapeutic drug, shows adherence reduction of Giardia trophozoites in vitro but the development of natural in vivo resistance limits its suitability for the control of giardiasis [148]. The giardicidal effects of triazolyl-quinolone-based chalcone derivatives depends on the presence or absence of oxygen [149]. Also, giardicidal effects of substances like allicin, propolis, tenatoprazole, fabomotizole, tenatoprazole and ipriflavone have been suggested [150, 151]. Some giardicidal substances have been newly identified from collections of bio-active compounds like the malaria venture's pathogen box. Components of such collections have been specifically chosen to stimulate infectious disease drug discovery. Various drugs of interest with potential giardicidal effects are only coded so far, like, e.g., MMV676358 and MMV028694 [152].

\section{CONCLUSIONS}

Several conclusions can be drawn from the available data on antimicrobial resistance in $G$. duodenalis. The recorded multiple realizability of resistance, which can be mediated by various factors influencing the expression of multiple effector proteins without specific target gene mutations [62], is most likely due to epigenetic or posttranslational modifications $[44,46,48,52,70]$ and does not require 
unambiguously identifiable patterns in proteomic assays [55]. Based on these findings including the results of comparative proteomics [55], it is highly unlikely to assume that rapid and easy-to-perform molecular assays for the detection of antimicrobial resistance will be available in the near future. Hence, testing of antimicrobial resistance in human $G$. duodenalis strains in order to allow resistancebased treatments will remain challenging. Although animal models for the assessment of $G$. duodenalis resistance against metronidazole and albendazole have been introduced to replace even more laborious culture procedures [153], resistance testing applying mouse models will nevertheless be poorly suitable for the diagnostic routine situation under the most circumstances. Standardization of resistance testing for G. duodenalis in microtiter plates about 3 days has been attempted as well [154]. For example, the trophozoite adherence inhibition method can be applied after in vitro excystation and axenical cultivation in TYI-S-33 modified medium as described [155]. But again, broad diagnostic implementation never succeeded. As recently shown, results of culture-based resistance testing also depend on whether the test is performed under anaerobic or microaerophilic conditions [149] and are affected by cysteine concentrations in the growth medium [156]. Further, phenotypic resistance testing is challenged by subpopulations of differing resistance levels even within the same G. duodenalis strain [35]. Thus standardization of both methodology and interpretation will be crucial if implementation in the routine laboratory diagnostic setting shall succeed.

Because culture of clinical $G$. duodenalis isolates is quite challenging and poorly compatible with diagnostic routine procedures so far, whole genome sequencing of parasite genomes has been proposed as a screening option for resistance determinants. In order to do so, purification of G. duodenalis from stool samples based on immunomagnetic separation after sucrose gradient flotation has been introduced [157]. However, as long as resistance determinants are poorly characterized, phenotypic resistance shows lacking stability [31] and epigenetic or post-translational modifications are often more relevant than DNA sequence changes $[44,46,48,52,70]$, a practical value of solely sequence-based resistance testing for the diagnostic routine as guidance for antimicrobial therapy of giardiasis remains doubtful.

Without reliable in vitro diagnostic assays indicating antimicrobial resistance or susceptibility, however, therapy of chronic therapy-refractory giardiasis remains a considerable challenge. Accordingly, a whole bundle of management efforts has been suggested, comprising the recognition of the known modifiable causes of this health condition, the assessment of symptoms and potential complications as well as - if necessary - their treatment utilizing a multidisciplinary therapeutic team and an ongoing monitoring of the effects of therapy [158]. However, also multidisciplinary therapeutic teams will have to rely on evidence, but evidence for the treatment of therapy-refractory giardiasis is scarce.

In order to provide such evidence, sufficiently powered, randomized controlled trials should be conducted as suggested previously $[16,102,103]$. In order to include sufficient numbers of patients with therapy-refractory giardiasis, multicentric studies will be preferable. Although a lot of potentially promising therapeutic approaches have been introduced above, focus on already available drugs will most likely be the best strategy to provide evidence in the near future. Next to the choice of optimal substances or substance combinations, optimal dosages for the treatment of G. duodenalis should be addressed in future studies, as suboptimal dosing regimens are likely to contribute to the resistance problem $[1,159]$. Further, a study focus should be on predisposing factors of therapy failure [17]. For example, studies on the effects of therapy adherence on therapy failure and resistance development might provide beneficial insights.

Next to sufficient numbers of included patients, adequate case definitions [160], precise knowledge of diagnostic characteristics of applied diagnostic tests [161] and appropriate surrogate parameters of the outcome [162] are critical in order to achieve meaningful study results by applying accuracy-adjusted estimators $[163,164]$. If, as shown before [13], reliability of microscopy-based parasite diagnostics is limited, molecular assays should be considered [11, 12], although molecular diagnostic tests for parasitic disease are still scarcely applied [165]. Thereby, PCR-based therapy control has to consider that DNA clearance from stool, either by excretion or nucleases, is a stochastic process. In literature, contradicting reports of DNA persistence after cleared infections between few days and several weeks within the complex stool matrix exist [166, 167]. Based on the experience at the German National Reference Centre for Tropical Pathogens Bernhard Nocht Insititute for Tropical Medicine Hamburg, G. duodenalis DNA should be cleared from stool at least 14 days after the end of a successful therapy. However, spontaneous cure of giardiasis has to be considered as well when estimating the patient numbers to be included [4]. Suggestions to overcome obstacles for the study design are included in Table 1. A major challenge for

Table 1. Suggestions to circumvent obstacles for therapeutic studies on optimal treatment of therapy-refractory giardiasis

\begin{tabular}{cc}
\hline Obstacle & Circumvention strategy \\
\hline $\begin{array}{c}\text { Low numbers of patients with } \\
\text { therapy-refractory giardiasis }\end{array}$ & $\begin{array}{c}\text { Multi-centric trials and focusing } \\
\text { on limited numbers of } \\
\text { treatment arms with drugs, } \\
\text { dosages and drug combinations } \\
\text { Combination of culture-based, } \\
\text { sequence-based and } \\
\text { diagnostics for antimicrobial } \\
\text { resistance in G. duodenalis } \\
\text { comparative proteomics } \\
\text { approaches as well as clinical } \\
\text { microscopy for the outcome } \\
\text { assessment }\end{array}$ \\
$\begin{array}{c}\text { and diagnostic case definitions } \\
\text { Imperfect accuracy of case } \\
\text { definitions }\end{array}$ & $\begin{array}{c}\text { PCR approaches in } \\
\text { combination with clinical case } \\
\text { definitions }\end{array}$ \\
& $\begin{array}{c}\text { Assessment of sensitivities and } \\
\text { specificities in pilot studies, then } \\
\text { application of accuracy adjusted } \\
\text { estimators }\end{array}$ \\
\hline
\end{tabular}


studies on the optimal treatment of giardiasis is the underlying economics, as it is considered as a neglected disease with low funding priority and limited commercial interest $[159,168]$. Accordingly, the topic will most likely have to remain in the scope of not-for-profit research activities.

Last not least, next to the development and implementation of new therapeutic strategies, infection prevention should not be neglected. Therefore, studies on successful enforcement of adequate hygiene standards to reduce both the transmission of $G$. duodenalis and the infectious burden will remain an issue of relevance [169]. Further, due to the difficult-to-control resistance conditions including the risk of multidrug resistance in G. duodenalis [170], also vaccine development remains an ongoing issue for the control of giardiasis [171].

Conflict of interest: Nothing to declare.

Funding sources:: No financial support was received for this study.

Authors' contribution: UL and HF jointly planned, wrote and reviewed the manuscript.

\section{REFERENCES}

1. Vivancos V, González-Alvarez I, Bermejo M, Gonzalez-Alvarez M. Giardiasis: characteristics, pathogenesis and new insights about treatment. Curr Top Med Chem 2018;18:1287-303.

2. Frickmann H, Schwarz NG, Rakotozandrindrainy R, May J, Hagen RM. PCR for enteric pathogens in high-prevalence settings. What does a positive signal tell us? Infect Dis (Lond) 2015;47:491-8.

3. Kann S, Bruennert D, Hansen J, Mendoza GAC, Gonzalez JJC, Quintero CLA, et al. High prevalence of intestinal pathogens in indigenous in Colombia. J Clin Med 2020;9:2786.

4. Leung AKC, Leung AAM, Wong AHC, Sergi CM, Kam JKM. Giardiasis: an overview. Recent Pat Inflamm Allergy Drug Discov 2019;13:134-43.

5. Frickmann H, Schwarz NG, Wiemer DF, Fischer M, Tannich E, Scheid PL, et al. Food and drinking water hygiene and intestinal protozoa in deployed German soldiers. Eur J Microbiol Immunol (Bp) 2013;3:53-60.

6. Frickmann H, Warnke P, Frey C, Schmidt S, Janke C, Erkens K, et al. Surveillance of food- and smear-transmitted pathogens in European soldiers with diarrhea on deployment in the tropics: experience from the European union training mission (EUTM) Mali. Biomed Res Int 2015;2015:573904.

7. Halfter M, Müseler U, Hagen RM, Frickmann H. Enteric pathogens in German police officers after predominantly tropical deployments - a retrospective assessment over 5 years. Eur J Microbiol Immunol (Bp) 2020;10:172-7.

8. Schawaller M, Wiemer D, Hagen RM, Frickmann H. Infectious diseases in German military personnel after predominantly tropical deployments: a retrospective assessment over 13 years. BMJ Mil Health 2020. Epub ahead of print: https://doi.org/10.1136/ bmjmilitary-2020-001575.
9. Wiemer D, Schwarz NG, Burchard GD, Frickmann H, Loderstaedt U, Hagen RM. Surveillance of enteropathogenic bacteria, protozoa and helminths in travellers returning from the tropics. Eur J Microbiol Immunol (Bp) 2020;10:147-55.

10. Maßßen W, Wiemer D, Frey C, Kreuzberg C, Tannich E, Hinz R, et al. Microbiological screenings for infection control in unaccompanied minor refugees: the German Armed Forces Medical Service's experience. Mil Med Res 2017;4:13.

11. Frickmann H, Hoffmann T, Köller T, Hahn A, Podbielski A, Landt $\mathrm{O}$, et al. Comparison of five commercial real-time PCRs for in-vitro diagnosis of Entamoeba histolytica, Giardia duodenalis, Cryptosporidium spp., Cyclospora cayetanensis, and Dientamoeba fragilis in human stool samples. Travel Med Infect Dis 2021;41:102042.

12. Köller T, Hahn A, Altangerel E, Verweij JJ, Landt O, Kann S, et al. Comparison of commercial and in-house real-time PCR platforms for 15 parasites and microsporidia in human stool samples without a gold standard. Acta Trop 2020;207:105516.

13. Utzinger J, Botero-Kleiven S, Castelli F, Chiodini PL, Edwards H, Köhler N, et al. Microscopic diagnosis of sodium acetate-acetic acid-formalin-fixed stool samples for helminths and intestinal protozoa: a comparison among European reference laboratories. Clin Microbiol Infect 2010;16:267-73.

14. Mørch K, Hanevik K. Giardiasis treatment: an update with a focus on refractory disease. Curr Opin Infect Dis 2020;33:355-64.

15. Leitsch D. Drug resistance in the microaerophilic parasite Giardia lamblia. Curr Trop Med Rep 2015;2:128-35.

16. Nabarro LE, Lever RA, Armstrong M, Chiodini PL. Increased incidence of nitroimidazole-refractory giardiasis at the hospital for tropical diseases, London: 2008-2013. Clin Microbiol Infect 2015; 21:791-6.

17. Debnath A, Reed SL, Morris SR. Predictors of failure from primary therapy for giardiasis in San Diego: a single institution retrospective review. Pathogens 2019;8:165.

18. Townson SM, Boreham PF, Upcroft P, Upcroft JA. Resistance to the nitroheterocyclic drugs. Acta Trop 1994;56:173-94.

19. Freeman CD, Klutman NE, Lamp KC. Metronidazole. A therapeutic review and update. Drugs 1997;54:679-708.

20. Barat LM, Bloland PB. Drug resistance among malaria and other parasites. Infect Dis Clin North Am 1997;11:969-87.

21. Smith PD, Gillin FD, Spira WM, Nash TE. Chronic giardiasis: studies on drug sensitivity, toxin production, and host immune response. Gastroenterology 1982;83:797-803.

22. Jaremin B, Bielawska-Krasnowiecka G. 2 cases of lambliasis, resistant to imidazole drugs, cured with atebrine. Wiad Lek 1983; 36:1105-7.

23. Gordts B, Hemelhof W, Asselman C, Butzler JP. In vitro susceptibilities of 25 Giardia lamblia isolates of human origin to six commonly used antiprotozoal agents. Antimicrob Agents Chemother 1985;28:378-80.

24. Majewska AC, Kasprzak W, De Jonckheere JF, Kaczmarek E. Heterogeneity in the sensitivity of stocks and clones of Giardia to metronidazole and ornidazole. Trans R Soc Trop Med Hyg 1991; 85:67-9.

25. Rosenblatt JE. Antiparasitic agents. Mayo Clin Proc 1992;67: 276-87.

26. Rowedder A, Meier R, Wegmann W, Gyr K. Combined oral and endoscopic mepacrine therapy in therapy-resistant symptomatic giardiasis. Schweiz Med Wochenschr 1991;121:1383-6. 
27. Upcroft JA, Upcroft P. Drug resistance and Giardia. Parasitol Today 1993;9:187-90.

28. Gardner TB, Hill DR. Treatment of giardiasis. Clin Microbiol Rev 2001;14:114-28.

29. Upcroft P. Drug resistance in Giardia: clinical versus laboratory isolates. Drug Resist Updat 1998;1:166-8.

30. Deyab FA, El-Nouby KA, Shoheib ZS, El-Fadl AA. Effect of organochlorine (DDT) exposure on experimental giardiasis. J Egypt Soc Parasitol 2008;38:225-41.

31. Boreham PF, Phillips RE, Shepherd RW. Altered uptake of metronidazole in vitro by stocks of Giardia intestinalis with different drug sensitivities. Trans R Soc Trop Med Hyg 1988;82:104-6.

32. Townson SM, Laqua H, Upcroft P, Boreham PF, Upcroft JA. Induction of metronidazole and furazolidone resistance in Giardia. Trans R Soc Trop Med Hyg 1992;86:521-2.

33. Lindquist HD. Induction of albendazole resistance in Giardia lamblia. Microb Drug Resist 1996;2:433-4.

34. Upcroft JA, Campbell RW, Upcroft P. Quinacrine-resistant Giardia duodenalis. Parasitology 1996;112(Pt 3):309-13.

35. Argüello-García R, Cruz-Soto M, Romero-Montoya L, OrtegaPierres G. Variability and variation in drug susceptibility among Giardia duodenalis isolates and clones exposed to 5-nitroimidazoles and benzimidazoles in vitro. J Antimicrob Chemother 2004;54:711-21.

36. Johnson PJ. Metronidazole and drug resistance. Parasitol Today 1993;9:183-6.

37. Borst P, Ouellette M. New mechanisms of drug resistance in parasitic protozoa. Annu Rev Microbiol 1995;49:427-60.

38. Land KM, Johnson PJ. Molecular basis of metronidazole resistance in pathogenic bacteria and protozoa. Drug Resist Updat 1999;2: 289-94.

39. Smith NC, Bryant C, Boreham PF. Possible roles for pyruvate: ferredoxin oxidoreductase and thiol-dependent peroxidase and reductase activities in resistance to nitroheterocyclic drugs in Giardia intestinalis. Int J Parasitol 1988;18:991-7.

40. Upcroft P, Upcroft JA. Drug targets and mechanisms of resistance in the anaerobic protozoa. Clin Microbiol Rev 2001;14:150-64.

41. Upcroft JA, Upcroft P, Boreham PF. Drug resistance in Giardia intestinalis. Int J Parasitol 1990;20:489-96.

42. Liu SM, Brown DM, O’Donoghue P, Upcroft P, Upcroft JA. Ferredoxin involvement in metronidazole resistance of Giardia duodenalis. Mol Biochem Parasitol 2000;108:137-40.

43. Galeh TM, Kazemi A, Mahami-Oskouei M, Baradaran B, Spotin A, Sarafraz S, et al. Introducing nitazoxanide as a promising alternative treatment for symptomatic to metronidazole-resistant giardiasis in clinical isolates. Asian Pac J Trop Med 2016;9:887-92.

44. Ansell BR, Baker L, Emery SJ, McConville MJ, Svärd SG, Gasser $\mathrm{RB}$, et al. Transcriptomics indicates active and passive metronidazole resistance mechanisms in three seminal Giardia lines. Front Microbiol 2017;8:398.

45. Pal D, Banerjee S, Cui J, Schwartz A, Ghosh SK, Samuelson J. Giardia, Entamoeba, and Trichomonas enzymes activate metronidazole (nitroreductases) and inactivate metronidazole (nitroimidazole reductases). Antimicrob Agents Chemother 2009;53: 458-64.

46. Ansell BR, McConville MJ, Ma'ayeh SY, Dagley MJ, Gasser RB, Svärd SG, et al. Drug resistance in Giardia duodenalis. Biotechnol Adv 2015;33(6 Pt 1):888-901.
47. Ordoñez-Quiroz A, Ortega-Pierres MG, Bazán-Tejeda ML, Bermúdez-Cruz RM. DNA damage induced by metronidazole in Giardia duodenalis triggers a DNA homologous recombination response. Exp Parasitol 2018;194:24-31.

48. Emery SJ, Baker L, Ansell BRE, Mirzaei M, Haynes PA, McConville MJ, et al. Differential protein expression and post-translational modifications in metronidazole-resistant Giardia duodenalis. Gigascience 2018;7:giy024.

49. Hoyne GF, Boreham PF, Parsons PG, Ward C, Biggs B. The effect of drugs on the cell cycle of Giardia intestinalis. Parasitology 1989; 99(Pt 3):333-9.

50. Ellis JE, Wingfield JM, Cole D, Boreham PF, Lloyd D. Oxygen affinities of metronidazole-resistant and -sensitive stocks of Giardia intestinalis. Int J Parasitol 1993;23:35-9.

51. Tejman-Yarden N, Eckmann L. New approaches to the treatment of giardiasis. Curr Opin Infect Dis 2011;24:451-6.

52. Müller J, Ley S, Felger I, Hemphill A, Müller N. Identification of differentially expressed genes in a Giardia lamblia WB C6 clone resistant to nitazoxanide and metronidazole. J Antimicrob Chemother 2008;62:72-82.

53. Nillius D, Müller J, Müller N. Nitroreductase (GINR1) increases susceptibility of Giardia lamblia and Escherichia coli to nitro drugs. J Antimicrob Chemother 2011;66:1029-35.

54. Müller J, Hemphill A, Müller N. Physiological aspects of nitro drug resistance in Giardia lamblia. Int J Parasitol Drugs Drug Resist 2018;8:271-7.

55. Müller J, Braga S, Heller M, Müller N. Resistance formation to nitro drugs in Giardia lamblia: No common markers identified by comparative proteomics. Int J Parasitol Drugs Drug Resist 2019;9: $112-9$.

56. Upcroft J, Mitchell R, Chen N, Upcroft P. Albendazole resistance in Giardia is correlated with cytoskeletal changes but not with a mutation at amino acid 200 in beta-tubulin. Microb Drug Resist 1996;2:303-8.

57. Jiménez-Cardoso E, Eligio-García L, Cortés-Campos A, FloresLuna A, Valencia-Mayoral P, Lozada-Chávez I. Changes in betagiardin sequence of Giardia intestinalis sensitive and resistant to albendazole strains. Parasitol Res 2009;105:25-33.

58. Ángeles-Arvizu A, Enriquez-Flores S, Jiménez-Gutiérrez A, PérezRangel A, Luna-Arias JP, Castillo-Romero A, et al. MDR1 protein (ABC-C1) over expression in giardia intestinalis incubated with albendazole and nitazoxanide. Acta Parasitol 2021. [Epub ahead of print]: https://doi.org/10.1007/s11686-021-00385-5.

59. Argüello-García R, Cruz-Soto M, González-Trejo R, Paz-Maldonado LM, Bazán-Tejeda ML, Mendoza-Hernández G, et al. An antioxidant response is involved in resistance of Giardia duodenalis to albendazole. Front Microbiol 2015;6:286.

60. Leitsch D, Schlosser S, Burgess A, Duchêne M. Nitroimidazole drugs vary in their mode of action in the human parasite Giardia lamblia. Int J Parasitol Drugs Drug Resist 2012;2:166-70.

61. Liu J, Chen D, Peters BM, Li L, Li B, Xu Z, et al. Staphylococcal chromosomal cassettes mec (SCCmec): a mobile genetic element in methicillin-resistant Staphylococcus aureus. Microb Pathog 2016;101:56-67.

62. Lopes-Oliveira LAP, Fantinatti M, Da-Cruz AM. In vitro-induction of metronidazole-resistant Giardia duodenalis is not associated with nucleotide alterations in the genes involved in pro-drug activation. Mem Inst Oswaldo Cruz 2020;115:e200303. 
63. Saghaug CS, Klotz C, Kallio JP, Brattbakk HR, Stokowy T, Aebischer $\mathrm{T}$, et al. Genetic variation in metronidazole metabolism and oxidative stress pathways in clinical Giardia lamblia assemblage A and B isolates. Infect Drug Resist 2019;12:1221-35.

64. Upcroft JA, Healey A, Murray DG, Boreham PF, Upcroft P. A gene associated with cell division and drug resistance in Giardia duodenalis. Parasitology 1992;104(Pt 3):397-405.

65. Müller J, Sterk M, Hemphill A, Müller N. Characterization of Giardia lamblia WB C6 clones resistant to nitazoxanide and to metronidazole. J Antimicrob Chemother 2007;60:280-7.

66. Argüello-García R, Cruz-Soto M, Romero-Montoya L, OrtegaPierres G. In vitro resistance to 5-nitroimidazoles and benzimidazoles in Giardia duodenalis: variability and variation in gene expression. Infect Genet Evol 2009;9:1057-64.

67. Begaydarova R, Yukhnevich Y, Babenko D, Kaliyeva S, Azizov I, Muldaeva $G$, et al. Determination of PFOR gene expression in strains of $G$. intestinalis with different inhibitory concentrations of metronidazole. J Infect Dev Ctries 2015;9:519-23.

68. Dunn LA, Burgess AG, Krauer KG, Eckmann L, Vanelle P, Crozet $\mathrm{MD}$, et al. A new-generation 5-nitroimidazole can induce highly metronidazole-resistant Giardia lamblia in vitro. Int J Antimicrob Agents 2010;36:37-42.

69. Leitsch D, Burgess AG, Dunn LA, Krauer KG, Tan K, Duchêne M, et al. Pyruvate:ferredoxin oxidoreductase and thioredoxin reductase are involved in 5-nitroimidazole activation while flavin metabolism is linked to 5-nitroimidazole resistance in Giardia lamblia. J Antimicrob Chemother 2011;66:1756-65.

70. Ansell BR, McConville MJ, Baker L, Korhonen PK, Emery SJ, Svärd SG, et al. Divergent transcriptional responses to physiological and xenobiotic stress in Giardia duodenalis. Antimicrob Agents Chemother 2016;60:6034-45.

71. Uzlikova M, Nohynkova E. The effect of metronidazole on the cell cycle and DNA in metronidazole-susceptible and -resistant Giardia cell lines. Mol Biochem Parasitol 2014;198:75-81.

72. Aguayo-Ortiz R, Méndez-Lucio O, Romo-Mancillas A, Castillo R, Yépez-Mulia L, Medina-Franco JL, et al. Molecular basis for benzimidazole resistance from a novel $\beta$-tubulin binding site model. J Mol Graph Model 2013;45:26-37.

73. Paz-Maldonado MT, Argüello-García R, Cruz-Soto M, Mendoza-Hernández G, Ortega-Pierres G. Proteomic and transcriptional analyses of genes differentially expressed in Giardia duodenalis clones resistant to albendazole. Infect Genet Evol 2013;15:10-7.

74. Sterk M, Müller J, Hemphill A, Müller N. Characterization of a Giardia lamblia WB C6 clone resistant to the isoflavone formononetin. Microbiology (Reading) 2007;153(Pt 12):4150-8.

75. Yu DC, Wang AL, Wang CC. Stable coexpression of a drugresistance gene and a heterologous gene in an ancient parasitic protozoan Giardia lamblia. Mol Biochem Parasitol 1996;83:81-91.

76. Minenoa T, Avery MA. Giardiasis: recent progress in chemotherapy and drug development. Curr Pharm Des 2003;9:841-55.

77. Wright JM, Dunn LA, Upcroft P, Upcroft JA. Efficacy of antigiardial drugs. Expert Opin Drug Saf 2003;2:529-41.

78. Hart CJ, Munro T, Andrews KT, Ryan JH, Riches AG, SkinnerAdams TS. A novel in vitro image-based assay identifies new drug leads for giardiasis. Int J Parasitol Drugs Drug Resist 2017;7:83-9.

79. Upcroft JA, Campbell RW, Benakli K, Upcroft P, Vanelle P. Efficacy of new 5-nitroimidazoles against metronidazole-susceptible and -resistant Giardia, Trichomonas, and Entamoeba spp. Antimicrob Agents Chemother 1999;43:73-6.

80. Upcroft JA, Dunn LA, Wright JM, Benakli K, Upcroft P, Vanelle P. 5-Nitroimidazole drugs effective against metronidazole-resistant Trichomonas vaginalis and Giardia duodenalis. Antimicrob Agents Chemother 2006;50:344-7.

81. Miyamoto Y, Kalisiak J, Korthals K, Lauwaet T, Cheung DY, Lozano R, et al. Expanded therapeutic potential in activity space of next-generation 5-nitroimidazole antimicrobials with broad structural diversity. Proc Natl Acad Sci U S A 2013;110:17564-9.

82. Valdez CA, Tripp JC, Miyamoto Y, Kalisiak J, Hruz P, Andersen YS, et al. Synthesis and electrochemistry of 2-ethenyl and 2ethanyl derivatives of 5-nitroimidazole and antimicrobial activity against Giardia lamblia. J Med Chem 2009;52:4038-53.

83. Jarrad AM, Karoli T, Debnath A, Tay CY, Huang JX, Kaeslin G, et al. Metronidazole-triazole conjugates: activity against Clostridium difficile and parasites. Eur J Med Chem 2015;101:96-102.

84. Jarrad AM, Debnath A, Miyamoto Y, Hansford KA, Pelingon R, Butler MS, et al. Nitroimidazole carboxamides as antiparasitic agents targeting Giardia lamblia, Entamoeba histolytica and Trichomonas vaginalis. Eur J Med Chem 2016;120:353-62.

85. Busatti HG, Alves RJ, Santana-Anjos KG, Gil FF, Cury MC, Vannier-Santos MA, et al. Effects of metronidazole analogues on Giardia lamblia: experimental infection and cell organization. Diagn Microbiol Infect Dis 2013;75:160-4.

86. Kim WJ, Korthals KA, Li S, Le C, Kalisiak J, Sharpless KB, et al. Click chemistry-facilitated structural diversification of Nitrothiazoles, Nitrofurans, and Nitropyrroles enhances antimicrobial activity against Giardia lamblia. Antimicrob Agents Chemother 2017;61:e02397-16.

87. Hausen MA, Freitas JC, Jr, Monteiro-Leal LH. The effects of metronidazole and furazolidone during Giardia differentiation into cysts. Exp Parasitol 2006;113:135-41.

88. Leitsch D, Müller J, Müller N. Evaluation of Giardia lamblia thioredoxin reductase as drug activating enzyme and as drug target. Int J Parasitol Drugs Drug Resist 2016;6:148-53.

89. Edlind TD, Hang TL, Chakraborty PR. Activity of the anthelmintic benzimidazoles against Giardia lamblia in vitro. J Infect Dis 1990 Dec;162(6):1408-11.

90. Morgan UM, Reynoldson JA, Thompson RC. Activities of several benzimidazoles and tubulin inhibitors against Giardia spp. in vitro. Antimicrob Agents Chemother 1993;37:328-31.

91. O’Handley RM, Olson ME, McAllister TA, Morck DW, Jelinski M, Royan G, et al. Efficacy of fenbendazole for treatment of giardiasis in calves. Am J Vet Res 1997;58:384-8.

92. Andrzejewska M, Yepez-Mulia L, Tapia A, Cedillo-Rivera R, Laudy AE, Starościak BJ, et al. Synthesis, and antiprotozoal and antibacterial activities of S-substituted 4,6-dibromo- and 4,6-dichloro-2mercaptobenzimidazoles. Eur J Pharm Sci 2004;21:323-9.

93. Jiménez-Cardoso E, Flores-Luna A, Pérez-Urizar J. In vitro activity of two phenyl-carbamate derivatives, singly and in combination with albendazole against albendazole-resistant Giardia intestinalis. Acta Trop 2004;92:237-44.

94. Hausen MA, de Oliveira RP, Gadelha AP, Campanati L, de Carvalho JJ, de Carvalho L, et al. Giardia lamblia: a report of drug effects under cell differentiation. Parasitol Res 2009;105:789-96.

95. Aguilar-Díaz H, Carrero JC, Argüello-García R, Laclette JP, Morales-Montor J. Cyst and encystment in protozoan parasites: 
optimal targets for new life-cycle interrupting strategies? Trends Parasitol 2011;27:450-8.

96. Solaymani-Mohammadi S, Genkinger JM, Loffredo CA, Singer SM. A meta-analysis of the effectiveness of albendazole compared with metronidazole as treatments for infections with Giardia duodenalis. Plos Negl Trop Dis 2010;4:e682.

97. Martínez-Espinosa R, Argüello-García R, Saavedra E, OrtegaPierres G. Albendazole induces oxidative stress and DNA damage in the parasitic protozoan Giardia duodenalis. Front Microbiol 2015;6:800.

98. Ponce-Macotela M, Gómez-Garduño J, González-Maciel A, Reynoso-Robles R, Anislado-Tolentino V, Martínez-Gordillo MN. In vitro measurement of nitazoxanide sensitivity of 4 Giardia duodenalis isolates obtained from different hosts. Rev Invest Clin 2001;53:41-5.

99. Adagu IS, Nolder D, Warhurst DC, Rossignol JF. In vitro activity of nitazoxanide and related compounds against isolates of Giardia intestinalis, Entamoeba histolytica and Trichomonas vaginalis. J Antimicrob Chemother 2002;49:103-11.

100. Abboud P, Lemée V, Gargala G, Brasseur P, Ballet JJ, Borsa-Lebas F, et al. Successful treatment of metronidazole- and albendazoleresistant giardiasis with nitazoxanide in a patient with acquired immunodeficiency syndrome. Clin Infect Dis 2001;32:1792-4.

101. Müller J, Rout S, Leitsch D, Vaithilingam J, Hehl A, Müller N. Comparative characterisation of two nitroreductases from Giardia lamblia as potential activators of nitro compounds. Int J Parasitol Drugs Drug Resist 2015;5:37-43.

102. Requena-Méndez A, Goñi P, Rubio E, Pou D, Fumadó V, Lóbez S, et al. The use of quinacrine in nitroimidazole-resistant Giardia Duodenalis: an old drug for an emerging problem. J Infect Dis 2017;215:946-53.

103. Cañete R, Noda AL, Rodríguez M, Brito K, Herrera E, Kofoed PE, et al. 5-Nitroimidazole refractory giardiasis is common in Matanzas, Cuba and effectively treated by secnidazole plus high-dose mebendazole or quinacrine: a prospective observational cohort study. Clin Microbiol Infect 2020;26:1092.e1-e6.

104. Edlind TD. Susceptibility of Giardia lamblia to aminoglycoside protein synthesis inhibitors: correlation with rRNA structure. Antimicrob Agents Chemother 1989;33:484-8.

105. Edlind TD, Cha ME, Prah GN, Katiyar SK. Domain V of Giardia lamblia large-subunit rRNA: structure of the peptidyl transferase loop from an early-branching eukaryote and correlation with antibiotic sensitivity. Gene 1993;124:67-74.

106. Katiyar SK, Visvesvara GS, Edlind TD. Comparisons of ribosomal RNA sequences from amitochondrial protozoa: implications for processing, mRNA binding and paromomycin susceptibility. Gene 1995;152:27-33.

107. Sousa MC, Poiares-da-Silva J. The cytotoxic effects of ciprofloxacin in Giardia lamblia trophozoites. Toxicol In Vitro 2001;15: 297-301.

108. Crouch AA, Seow WK, Whitman LM, Thong YH. Sensitivity in vitro of Giardia intestinalis to dyadic combinations of azithromycin, doxycycline, mefloquine, tinidazole and furazolidone. Trans R Soc Trop Med Hyg 1990;84:246-8.

109. Andrews BJ, Mylvaganam H, Yule A. Sensitivity of Trichomonas vaginalis, Tritrichomonas foetus and Giardia intestinalis to bacitracin and its zinc salt in vitro. Trans R Soc Trop Med Hyg 1994; 88:704-6.
110. Dunn LA, Andrews KT, McCarthy JS, Wright JM, Skinner-Adams TS, Upcroft $\mathrm{P}$, et al. The activity of protease inhibitors against Giardia duodenalis and metronidazole-resistant Trichomonas vaginalis. Int J Antimicrob Agents 2007;29:98-102.

111. Tejman-Yarden N, Miyamoto Y, Leitsch D, Santini J, Debnath A, Gut J, et al. A reprofiled drug, auranofin, is effective against metronidazole-resistant Giardia lamblia. Antimicrob Agents Chemother 2013;57:2029-35.

112. Eissa MM, Amer EI. Giardia lamblia: a new target for miltefosine. Int J Parasitol 2012;42:443-52.

113. Camerini S, Bocedi A, Cecchetti S, Casella M, Carbo M, Morea V, et al. Proteomic and functional analyses reveal pleiotropic action of the anti-tumoral compound NBDHEX in Giardia duodenalis. Int J Parasitol Drugs Drug Resist 2017;7:147-58.

114. Velázquez-Olvera S, Salgado-Zamora H, Jiménez-Cardoso E, Campos-Aldrete ME, Pérez-González C, Ben Hadda T. In vitro anti-Giardia lamblia activity of 2-aryl-3-hydroxymethyl imidazo [1,2-a]pyridines and -pyrimidines, individually and in combination with albendazole. Acta Trop 2016;155:6-10.

115. Escobedo AA, Lalle M, Hrastnik NI, Rodríguez-Morales AJ, Castro-Sánchez E, Cimerman S, et al. Combination therapy in the management of giardiasis: what laboratory and clinical studies tell us, so far. Acta Trop 2016;162:196-205.

116. Carter ER, Nabarro LE, Hedley L, Chiodini PL. Nitroimidazolerefractory giardiasis: a growing problem requiring rational solutions. Clin Microbiol Infect 2018;24:37-42.

117. Cacopardo B, Patamia I, Bonaccorso V, Di Paola O, Bonforte S, Brancati G. Synergic effect of albendazole plus metronidazole association in the treatment of metronidazole-resistant giardiasis. Clin Ter 1995;146:761-7.

118. Nash TE, Ohl CA, Thomas E, Subramanian G, Keiser P, Moore TA. Treatment of patients with refractory giardiasis. Clin Infect Dis 2001;33:22-8.

119. Watkins RR, Eckmann L. Treatment of giardiasis: current status and future directions. Curr Infect Dis Rep 2014;16:396.

120. Matadamas-Martínez F, Nogueda-Torres B, Castillo R, Hernández-Campos A, Barrera-Valdes ML, León-Ávila G, et al. Characterisation of the in vitro activity of a Nitazoxanide-N-methyl- $1 \mathrm{H}$ benzimidazole hybrid molecule against albendazole and nitazoxanide susceptible and resistant strains of Giardia intestinalis and its in vivo giardicidal activity. Mem Inst Oswaldo Cruz 2020;115: e190348.

121. Harris JC, Plummer S, Lloyd D. Antigiardial drugs. Appl Microbiol Biotechnol 2001;57:614-19.

122. Agarwal AK, Singh M, Gupta N, Saxena R, Puri A, Verma AK, et al. Management of giardiasis by an immuno-modulatory herbal drug Pippali rasayana. J Ethnopharmacol 1994;44:143-6.

123. Meckes M, Calzada F, Tapia-Contreras A, Cedillo-Rivera R. Antiprotozoal properties of Helianthemum glomeratum. Phytother Res 1999;13:102-5.

124. Ponce-Macotela M, Rufino-González Y, González-Maciel A, Reynoso-Robles R, Martínez-Gordillo MN. Oregano (Lippia spp.) kills Giardia intestinalis trophozoites in vitro: antigiardiasic activity and ultrastructural damage. Parasitol Res 2006;98:557-60.

125. Rufino-González Y, Ponce-Macotela M, González-Maciel A, Reynoso-Robles R, Jiménez-Estrada M, Sánchez-Contreras Á, et al. In vitro activity of the F-6 fraction of oregano against Giardia intestinalis. Parasitology 2012;139:434-40. 
126. Anthony JP, Fyfe L, Stewart D, McDougall GJ, Smith HV. The effect of blueberry extracts on Giardia duodenalis viability and spontaneous excystation of Cryptosporidium parvum oocysts, in vitro. Methods 2007;42:339-48.

127. Dyab AK, Yones DA, Ibraheim ZZ, Hassan TM. Anti-giardial therapeutic potential of dichloromethane extracts of Zingiber officinale and Curcuma longa in vitro and in vivo. Parasitol Res 2016;115:2637-45.

128. Golami S, Rahimi-Esboei B, Mousavi P, Marhaba Z, Youssefi MR, Rahimi MT. Survey on efficacy of chloroformic extract of Artemisia annua against Giardia lamblia trophozoite and cyst in vitro. J Parasit Dis 2016;40:88-92.

129. Abd-Elhamid TH, Abdel-Rahman IAM, Mahmoud AR, Allemailem KS, Almatroudi A, Fouad SS, et al. A complementary herbal product for controlling giardiasis. Antibiotics (Basel) 2021; 10:477.

130. Fallahi S, Rostami A, Delfan B, Pournia Y, Rashidipour M. Effect of olive leaf, Satureja khuzestanica, and Allium sativum extracts on Giardia lamblia cysts compared with metronidazole in vitro. J Parasit Dis 2016;40:1204-9.

131. Drinić M, Raninger A, Zraunig A, Astelbauer F, Leitsch D, Obwaller A, et al. Activity of methylgerambullin from Glycosmis species (Rutaceae) against Entamoeba histolytica and Giardia duodenalis in vitro. Int J Parasitol Drugs Drug Resist 2019;10:109-17.

132. Cock IE, Rayan P. Ascorbic acid potentiates the Giardia duodenalis growth inhibitory activity of pure Terminalia ferdinandiana Exell compounds. Parasitol Res 2020;119:1125-37.

133. Pintong AR, Ruangsittichai J, Ampawong S, Thima K, Sriwichai P, Komalamisra N, et al. Efficacy of Ageratum conyzoides extracts against Giardia duodenalis trophozoites: an experimental study. BMC Complement Med Ther 2020;20:63.

134. Gillin FD, Reiner DS, Wang CS. Killing of Giardia lamblia trophozoites by normal human milk. J Cell Biochem 1983;23:47-56.

135. Turchany JM, Aley SB, Gillin FD. Giardicidal activity of lactoferrin and N-terminal peptides. Infect Immun 1995;63:4550-2.

136. Enríquez-Flores S, Rodríguez-Romero A, Hernández-Alcántara G, Oria-Hernández J, Gutiérrez-Castrellón P, Pérez-Hernández G, et al. Determining the molecular mechanism of inactivation by chemical modification of triosephosphate isomerase from the human parasite Giardia lamblia: a study for antiparasitic drug design. Proteins 2011;79:2711-24.

137. Reyes-Vivas H, de la Mora-de la Mora I, Castillo-Villanueva A, Yépez-Mulia L, Hernández-Alcántara G, Figueroa-Salazar R, et al. Giardial triosephosphate isomerase as possible target of the cytotoxic effect of omeprazole in Giardia lamblia. Antimicrob Agents Chemother 2014;58:7072-82.

138. Hernández-Ochoa B, Navarrete-Vázquez G, Nava-Zuazo C, Castillo-Villanueva A, Méndez ST, Torres-Arroyo A, et al. Novel giardicidal compounds bearing proton pump inhibitor scaffold proceeding through triosephosphate isomerase inactivation. Sci Rep 2017;7:7810.

139. Castillo-Villanueva A, Rufino-González Y, Méndez ST, TorresArroyo A, Ponce-Macotela M, Martínez-Gordillo MN, et al. Disulfiram as a novel inactivator of Giardia lamblia triosephosphate isomerase with antigiardial potential. Int J Parasitol Drugs Drug Resist 2017;7:425-32.

140. Chen CZ, Southall N, Galkin A, Lim K, Marugan JJ, Kulakova L, et al. A homogenous luminescence assay reveals novel inhibitors for giardia lamblia carbamate kinase. Curr Chem Genomics 2012;6: 93-102.

141. Gadelha APR, Bravim B, Vidal J, Reignault LC, Cosme B, Huber $\mathrm{K}$, et al. Alterations on growth and cell organization of Giardia intestinalis trophozoites after treatment with KH-TFMDI, a novel class III histone deacetylase inhibitor. Int J Med Microbiol 2019; 309:130-42.

142. Guo F, Ortega-Pierres G, Argüello-García R, Zhang H, Zhu G. Giardia fatty acyl-CoA synthetases as potential drug targets. Front Microbiol 2015;6:753.

143. Debnath A, Shahinas D, Bryant C, Hirata K, Miyamoto Y, Hwang $\mathrm{G}$, et al. Hsp90 inhibitors as new leads to target parasitic diarrheal diseases. Antimicrob Agents Chemother 2014;58:4138-44.

144. Travers MA, Sow C, Zirah S, Deregnaucourt C, Chaouch S, Queiroz RM, et al. Deconjugated bile salts produced by extracellular bile-salt hydrolase-like activities from the probiotic Lactobacillus johnsonii La1 inhibit Giardia duodenalis In vitro growth. Front Microbiol 2016;7:1453.

145. Abraham RJ, Abraham S, Stevens AJ, Page SW, McCluskey A, Trott DJ, et al. Aminoguanidines: new leads for treatment of Giardia duodenalis infection. Int J Parasitol Drugs Drug Resist 2019;10:38-44.

146. Hennessey KM, Smith TR, Xu JW, Alas GC, Ojo KK, Merritt EA, et al. Identification and validation of small-gatekeeper kinases as drug targets in Giardia lamblia. Plos Negl Trop Dis 2016;10:e0005107.

147. Popovic O, Jojic N, Milutinovic-Djuric S, Djurdjevic D, Milovic V. Propranolol for metronidazole-resistant giardiasis. Ital J Gastroenterol 1991;23:359.

148. McAllister TA, Annett CB, Olson ME, Morck DW, Cheng KJ. Effect of salinomycin on giardiasis and coccidiosis in growing lambs. J Anim Sci 1996;74:2896-903.

149. Bahadur V, Mastronicola D, Singh AK, Tiwari HK, Pucillo LP, Sarti $\mathrm{P}$, et al. Antigiardial activity of novel triazolyl-quinolonebased chalcone derivatives: when oxygen makes the difference. Front Microbiol 2015;6:256.

150. Argüello-García R, Leitsch D, Skinner-Adams T, Ortega-Pierres MG. Drug resistance in Giardia: mechanisms and alternative treatments for Giardiasis. Adv Parasitol 2020;107:201-82.

151. Pérez-Villanueva J, Yépez-Mulia L, Rodríguez-Villar K, CortésBenítez F, Palacios-Espinosa JF, Soria-Arteche O. The giardicidal activity of lobendazole, fabomotizole, tenatoprazole and ipriflavone: a ligand-based virtual screening and in vitro study. Eur J Med Chem 2021;211:113110.

152. Tiash S, Saunders J, Hart CJS, Ryan JH, Riches AG, SkinnerAdams TS, et al. An image-based Pathogen Box screen identifies new compounds with anti-Giardia activity and highlights the importance of assay choice in phenotypic drug discovery. Int J Parasitol Drugs Drug Resist 2020;12:60-7.

153. Lemée V, Zaharia I, Nevez G, Rabodonirina M, Brasseur P, Ballet $\mathrm{JJ}$, et al. Metronidazole and albendazole susceptibility of 11 clinical isolates of Giardia duodenalis from France. J Antimicrob Chemother 2000;46:819-21.

154. Upcroft JA, Upcroft P. Drug susceptibility testing of anaerobic protozoa. Antimicrob Agents Chemother 2001;45:1810-14.

155. Cruz A, Sousa MI, Azeredo Z, Leite E, Figueiredo de Sousa JC, Cabral M. Isolation, excystation and axenization of Giardia lamblia isolates: in vitro susceptibility to metronidazole and albendazole. J Antimicrob Chemother 2003;51:1017-20. 
156. Leitsch D. Drug susceptibility testing in microaerophilic parasites: cysteine strongly affects the effectivities of metronidazole and auranofin, a novel and promising antimicrobial. Int J Parasitol Drugs Drug Resist 2017;7:321-7.

157. Hanevik K, Bakken R, Brattbakk HR, Saghaug CS, Langeland N. Whole genome sequencing of clinical isolates of Giardia lamblia. Clin Microbiol Infect 2015;21:192.e1-e3.

158. Escobedo AA, Hanevik K, Almirall P, Cimerman S, Alfonso M. Management of chronic Giardia infection. Expert Rev Anti Infect Ther 2014;12:1143-57.

159. Miyamoto Y, Eckmann L. Drug development against the major diarrhea-causing parasites of the small intestine, Cryptosporidium and Giardia. Front Microbiol 2015;6:1208.

160. Hahn A, Frickmann H, Zautner AE. Impact of case definitions on efficacy estimation in clinical trials-A proof-of-principle based on historical examples. Antibiotics (Basel) 2020;9:379.

161. Hahn A, Meyer CG, Frickmann H. Impact of diagnostic methods on efficacy estimation - a proof-of-principle based on historical examples. Trop Med Int Health 2020;25:357-63.

162. Hahn A, Podbielski A, Heimesaat MM, Frickmann H, Warnke P. Binary surrogate endpoints in clinical trials from the perspective of case definitions. Eur J Microbiol Immunol (Bp) 2021;11:18-22.

163. Rogan WJ, Gladen B. Estimating prevalence from the results of a screening test. Am J Epidemiol 1978;107:71-6.
164. Flor M, Weiß M, Selhorst T, Müller-Graf C, Greiner M. Comparison of Bayesian and frequentist methods for prevalence estimation under misclassification. BMC Public Health 2020;20: 1135.

165. Hunt PW. Molecular diagnosis of infections and resistance in veterinary and human parasites. Vet Parasitol 2011;180:12-46.

166. Mejia R, Vicuña Y, Broncano N, Sandoval C, Vaca M, Chico M., et al. A novel, multi-parallel, real-time polymerase chain reaction approach for eight gastrointestinal parasites provides improved diagnostic capabilities to resource-limited at-risk populations. Am J Trop Med Hyg 2013;88:1041-7.

167. van den Bijllaardt W, Overdevest IT, Buiting AG, Verweij JJ. Rapid clearance of Giardia lamblia DNA from the gut after successful treatment. Clin Microbiol Infect 2014;20:O972-4.

168. Lalle M, Hanevik K. Treatment-refractory giardiasis: challenges and solutions. Infect Drug Resist 2018;11:1921-33.

169. Riches A, Hart CJS, Trenholme KR, Skinne r-Adams TS. AntiGiardia drug discovery: current status and gut feelings. J Med Chem 2020;63:13330-54.

170. Lalle M. Giardiasis in the post genomic era: treatment, drug resistance and novel therapeutic perspectives. Infect Disord Drug Targets 2010;10:283-94.

171. Tian HF, Chen B, Wen JF. Giardiasis, drug resistance, and new target discovery. Infect Disord Drug Targets 2010;10:295-302. 